\title{
Thermal stress induces dysfunction and facilitates senescence via disruption of cytoskeletal rearrangement and stimulation of the inflammatory response in primary endothelial cells
}

\section{Wei Zhao}

Jilin University First Hospital

\section{Bo Chen}

Jilin University First Hospital

Xi Zhang

Jilin University First Hospital

Shu-Yan Zhang

Jilin University First Hospital

\section{Xing Fan}

Jilin University First Hospital

Jia-Ao Yu

Jilin University First Hospital

Ke-Xin Chen ( $\square$ chenkexin@jlu.edu.cn )

Jilin University First Hospital https://orcid.org/0000-0002-1503-6044

\section{Research}

Keywords: Endothelial cell injury, Thermal stress, Cytoskeletal rearrangement, Inflammation

Posted Date: February 5th, 2021

DOI: https://doi.org/10.21203/rs.3.rs-184055/v1

License: (c) (i) This work is licensed under a Creative Commons Attribution 4.0 International License. Read Full License 


\section{Abstract}

\section{Background}

Thermal injury occurs when energy is transferred from a heat source to the body, causing local tissues to heat up. It has been demonstrated that the tissue temperature exceeds a certain threshold by exposure to external heat (thermal stress, TS), irreversible cell damage occurs, resulting in a delayed neovascularization. In recent years, warm paste is a popular item for people to keep warm in winter. Although the average temperature from the hot paste is only $54 \pm 3^{\circ} \mathrm{C}$, numerous cases of contact burns, that induced an increased capillary permeability in damaged tissue, by body warm paste were reported in our hospital.

Methods

Herein, we evaluated the damage to primary microvascular endothelial cells (ECs) at $45^{\circ} \mathrm{C}$ with various times and demonstrated that exposure to TS at $45^{\circ} \mathrm{C}$ only for 10 minutes induced irreversible damage in ECs via suppressed proliferation and promoted apoptosis.

Results

TS significantly delayed the cell cycle and facilitated senescence in primary ECs. ECs exposed to TS lost their motility, and cytoskeletal rearrangement resulted in impaired angiogenic function. Furthermore, the result from mRNA array revealed that TS induced not only a negative regulation of migration and branching structures, but also revealed that TS exposure promoted apoptotic processes and TNF signalling resulting in increased expression of pro-inflammatory factors, such as IL- $1 \beta$ and IL-6.

Conclusion

Taken together, our results indicate that burn injury may initiate systemic injury of the vascular system even at $45^{\circ} \mathrm{C}$ only for 10 minutes, which might be one of the mechanisms of delayed damaged tissue repair.

Trial registration

Not applicable.

\section{Introduction}

Thermal injury occurs when energy is transferred from a heat source to the body, causing local tissues to heat up. When the tissue temperature exceeds a certain threshold by exposure to external heat (thermal stress, TS), resulting in severe damage in subcutaneous tissues, such as skin, muscles, tendons and blood vessels (Jackson 1953). Moreover, TS has been proved to be responsible for disordered cell metabolism and mitochondrial damage causing cytotoxicity and cell death in a variety of cells (Jeschke 
et al. 2009, Szczesny et al. 2015, Porter et al. 2016). Accumulating evidence proves that a high external temperature can evoke vascular dysfunction, including cellular apoptosis, tissue damage and endothelial permeability, in the vascular system both in humans and laboratory animals (Lanier et al. 2011, Hirth et al. 2013). Damaged tissue repair and regeneration are affected by vascular injury, resulting in the prolonged hospitalization of burn patients (Werner and Grose 2003, Singh et al. 2007, Tiwari 2012).

Endothelial cells (ECs) play an important role as a blood vessel barrier in regulating the circulatory system (Aird 2007). In addition, EC injury can occur in vivo or in vitro in response to various stressors, such as TS and oxidative stress (Mittal et al. 2014, Meng et al. 2018). Endothelial dysfunction is a systemic disorder including impaired neovascularization, increased endothelial permeability and inhibited endothelial repair (Huang et al. 2016, McDonald et al. 2018). Furthermore, clinical and experimental data have demonstrated a close link between inflammation and dysfunction in damaged ECs, which secrete proinflammatory and pro-oxidative factors involved in various biological processes (Florea et al. 2013, Reho et al. 2019). Many in vitro studies have revealed that cellular damage caused by TS is dependent on the temperature and length of exposure (Log 2017). A recent report demonstrated that TS induced an upregulation of Hsp90 through the PI3K-Akt and PKM2 pathways in cardiac microvascular ECs (Zhang et al. 2020a).

In recent years, warm paste has become a daily item for people to keep warm in winter. However, thermal injury of skin caused by warm paste also increased, and we found that the integrity and permeability of blood vessels in the injured tissue was damaged. Previous study revealed that burns will not occur if the temperature is below $44^{\circ} \mathrm{C}$ (Moritz 1947). Here we report that TS induced an irreversible damage resulting in interruption of angiogenesis only with $45^{\circ} \mathrm{C}$ for 10 minutes in vascular endothelial cell.

\section{Materials And Methods}

\section{Primary EC isolation and culture}

C57BL/6 (B6) mice were obtained from Charles River (Beijing, China). Mouse primary ECs were isolated and purified as described in our previous study (Gao et al. 2016). Cells were cultured in M131 supplemented with $5 \%$ MVGS (Life Technologies). The purity of the isolated cells was determined by flow cytometry with anti-mouse CD31 antibody (BD Pharmingen). Heat exposure was performed with preheat medium at $45^{\circ} \mathrm{C}$ for indicated time in $\mathrm{CO}_{2}$ incubator.

\section{Cell proliferation assay}

Cell proliferation was assessed as described in our previous study (Gao et al. 2016). Briefly, cell proliferation was assessed using the cell counting kit-8 (CCK-8) assay kit (Beyotime). ECs were seeded into a 96 -well plate at $3 \times 10^{3}$ cells per well with $100 \mu$ of medium and cultured at $37^{\circ} \mathrm{C}$ in a $5 \% \mathrm{CO}_{2}$ incubator. CCK-8 solution was added ( $10 \mu$ l per well) 2 hours prior to measuring the absorbance at 450 $\mathrm{nm}$. 


\section{JC-1 assay}

EC apoptosis was estimated by mitochondrial disruption with a JC-1 mitochondrial membrane potential assay kit (Abcam, ab113850). Briefly, ECs were stained with $\mathrm{JC}$ solution for 10 minutes at $37^{\circ} \mathrm{C}$ and washed with dilution buffer. The aggregate dye can be excited at $535 \mathrm{~nm}$, and the monomer and aggregate can be excited together at $475 \mathrm{~nm}$.

\section{Senescence-associated $\beta$-galactosidase (SA- $\beta$-gal) activity analysis}

SA- $\beta$-gal activity was determined using a senescence $\beta$-galactosidase staining kit (Beyotime, Beijing) according to the manufacturer's instructions. ECs at different passages were plated in 12-well plates $\left(6 \times 10^{4} /\right.$ well) and analysed upon reaching $80-90 \%$ confluence. SA- $\beta$-gal-positive cells (i.e., senescent cells) were identified as green-stained cells under standard light microscopy, and the frequency of senescent cells was determined by counting approximately 500 cells in three random fields.

\section{Cell cycle analysis}

ECs were harvested by trypsinization upon reaching $80-90 \%$ confluence. Cells were washed twice with PBS, fixed at $-20^{\circ} \mathrm{C}$ in $70 \%$ ethanol for 12 hours, and stained in $300 \mathrm{ml}$ of propidium iodide (Pl; final concentration of $50 \mathrm{mg} / \mathrm{ml}$ ) and $0.1 \%$ Triton $X-100$ at $37^{\circ} \mathrm{C}$ for 15 minutes. The distribution of cells in different phases of the cell cycle was analysed by flow cytometry (BD FACS Canto II).

\section{Endothelial tube formation assay}

The tube formation assay was performed as described in our previous study (Gao et al. 2016). Briefly, Matrigel (Corning) was added to a 96 -well plate $(50 \mathrm{ml}$ per well) and allowed to polymerize for 30 minutes at $37^{\circ} \mathrm{C}$. ECs were seeded at $1 \times 10^{4}$ per well and grown in M131 supplemented with $5 \%$ MVGS for 24 hours at $37^{\circ} \mathrm{C}$ in a $5 \% \mathrm{CO} 2$ incubator. Images were acquired after 6 hours of incubation.

\section{Migration assay}

ECs were seeded at $2 \times 10^{5}$ per well in a 12-well plate and grown in M131 supplemented with $5 \%$ MVGS for 12 hours at $37^{\circ} \mathrm{C}$ in a $5 \% \mathrm{CO} 2$ incubator. The cells were starved with $0.5 \%$ FCS for 12 hours before a scratch was made. Images were acquired after 24 hours to examine migration.

\section{$\mathrm{RT}^{2}$ Profiler PCR Array and GO enrichment analysis}

Total RNA was isolated from ECs, and cDNA was synthesized using QuantiTect Reverse Transcription Kit (205311, Qiagen). mRNA expression profiling to compare endothelial biology between cells in the control and TS groups was performed using the real-time $\mathrm{RT}^{2}$ Profiler PCR Array (PAMM-015Z, QIAGEN) in combination with Hieff® qPCR SYBR Green Master Mix (11203ES03, YEASEN Biotech, Shanghai). Gene Ontology (GO) enrichment analysis of differentially expressed genes was implemented by the cluster Profiler R package, in which gene length bias was corrected. $G 0$ terms with corrected $P$ value less than 
0.05 were considered significantly enriched by differential expressed genes. The results from the PCR array were analysed by GO enrichment analysis. We first identified all statistically enriched terms, and accumulative hypergeometric $p$-values and enrichment factors were calculated and used for filtering.

\section{Quantitative real-time PCR}

Total RNA was extracted with TRIzol (Invitrogen, America), and cDNA was synthesized using Hifair® II 1st Strand cDNA Synthesis SuperMix for qPCR (11123ES60, YEASEN Biotech, Shanghai). Quantitative realtime PCR was performed using a Hieff ${ }^{\circledR}$ qPCR SYBR Green Master Mix (11203ES03, YEASEN Biotech, Shanghai) with a StepOnePlus real-time PCR system (ABI), and the primer sets used for IL-1b (sense: 5'TGGACCTTCCAGGATGAGGACA-3'; antisense: 5'-GTTCATCTCGGAGCCTGTAGTG-3'), IL-6 (sense: 5'CCTCTGGTCTTCTGGAGTACC-3'; antisense: 5'-ACTCCTTCTGTGACTCCAGC-3') and b-actin (sense: 5'TTCAACACCCCAGCCATG -3'; antisense: 5'- CCTCGTAGATGGGCACAGT -3') were purchased from Sangon Biotech (Shanghai). Relative gene expression was normalized to beta-actin.

\section{Stress fiber formation}

EC stress fiber formation was evaluated by staining F-actin with Alexa Fluor 546 phalloidin. Briefly, the ECs were seeded into 8-well chamber slides (Thermo Fisher, 154534) at $1 \times 10^{4} /$ well and fixed with $4 \%$ formaldehyde for 10 minutes at room temperature (RT) and then permeabilized with PBS (-) $0.1 \%$ Triton $\mathrm{X}-100$ at $4^{\circ} \mathrm{C}$ for 20 minutes. After washing three times with PBS, the cells were incubated with $1 \mathrm{U} / \mathrm{ml}$ Alexa Fluor 546 phalloidin for stress fiber staining or Alexa Fluor ${ }^{\circledR} 488$ SYTOX GREEN for nuclear staining at RT for 30 minutes.

\section{Statistical analysis}

All data are presented as the mean \pm SD, and significance was calculated by Student's $t$ test. Differences with $p<0.05$ were considered statistically significant.

\section{Results}

\section{TS suppressed proliferation and promoted apoptosis in primary ECs.}

Since previous study revealed that burns will not occur if the temperature is below $44^{\circ} \mathrm{C}$ (Moritz 1947). To assess the role of TS in EC injury, we investigated the effect of TS at $45^{\circ} \mathrm{C}$ on EC proliferation with various treated time. The result indicated that TS at $45^{\circ} \mathrm{C}$ for $10 \mathrm{~min}$ suppressed the viability of primary mice ECs with $51.8 \pm 3.9 \%$ in 96 hours later after the treatment (Supplementary data. 1). Thus, the condition was used in all subsequent TS treatment in vitro. TS exposure at $45^{\circ} \mathrm{C}$ for 10 minutes significantly suppressed EC proliferation compared to the control, and an apoptotic-like phenotype was observed (Fig. 1a and b) 96 hours after TS exposure. The viability of ECs was assessed by mitochondrial membrane potential assay (JC-1, Fig. 1C). ECs exposed to TS showed more damage than the control ECs, with $80 \%$ green 
fluorescence (Fig. 1d). These findings indicate that TS exposure suppressed EC viability and promoted apoptosis.

\section{TS facilitated senescence and delayed the cell cycle.}

To determine the role of TS in EC senescence, we detected SA-b-gal activity, a representative feature of senescence, in ECs during continuous cultivation. TS led to a marked increase in the percentage of SA-bgal+ ECs (26\%) at 24 hours after exposure (Fig. 2a and b). Cell cycle arrest is one of the most important features of senescence and an essential marker for identifying cellular senescence in vivo and in vitro (Kuilman et al. 2010). The cell cycle distribution was analysed by measuring DNA content. The percentage of cells in S phase was significantly greater in the control group (28\%) than in the TS group (15\%) (Fig. 2c). These results revealed that TS exposure facilitated senescence and delayed the cell cycle in ECs.

\section{TS suppressed tube formation and cellular motility via disruption of cytoskeletal rearrangement in ECs.}

In mammalian tissues, stress fibers play an important role in ECs, epithelial cells and myofibroblasts by modulating their motility and essential functions (Tojkander et al. 2012). Here, stress fiber formation was confirmed by confocal microscopy at 48 hours after TS exposure. TS exposure potently suppressed stress fiber formation (Fig. 3a). The F-actin intensity dropped by approximately $50 \%$ after TS exposure (Fig. 3b). Tube formation is the most widely applied function of ECs in the reorganization stage of angiogenesis. Therefore, tube formation was assessed at 48 hours after TS exposure and showed that TS exposure induced a significant decrease in the endothelial tube length and number of branch points compared to the control (Fig. 3c). The number of branches in the TS group was 32 per field less than that in the control group (45 per field). Furthermore, we assessed the effect of TS exposure on cellular motility by scratch assay at 24 hours after TS exposure. ECs exposed to TS showed inhibited migration, with a migration rate $60 \%$ that of the control cells (Fig. 3e and f). Our results suggest that TS exposure suppressed the angiogenic ability of ECs by disrupting stress fiber formation.

\section{TS altered EC biology-related gene expression and upregulated pro-inflammatory factor expression in ECs.}

We also assessed the changes in mRNA levels caused by TS exposure using a qPCR array, which profiles the expression of 84 genes related to EC biology (Fig. 4a). The changes then were analysed by GO enrichment analysis (Fig. 4b). The results were not only consistent with our other findings, which included negative regulation of migration and branching structures, but also revealed that TS exposure promoted apoptotic processes and TNF signalling. Since TNF signalling induces inflammatory factor expression, the mRNA levels of IL- $1 \mathrm{~b}$ and IL- 6 were detected by real-time qPCR (Fig. 5a and b). TS upregulated the mRNA level of IL- 1 b by 2.2 -fold and that of IL- 6 by 3.6-fold compared to the control at 24 hours after exposure.

\section{Conclusion And Discussion}


Burn injury is a global public health issue that involves long-term hospital care, disability and disfigurement. Poor wound healing is mainly determined by early events in the repair process (Church et al. 2006). Rebuilding the blood supply is a critical process and beneficial for improving tissue repair, especially in cases of burn injury (Zhang et al. 2010). Since angiogenesis ensures perfusion of the regenerated tissue, inhibited angiogenesis may yield a poorly vascularized microenvironment for granulation tissue growth, resulting in skin graft failure in cases of severe burns. Therefore, EC viability and functions, such as migration, polarization, and tube formation, are critical for neovascularization. A high external temperature triggers systemic disorder and damage, including an inflammatory response, hypermetabolic activity and EC dysfunction, in skin tissue as a whole. Increasing evidence shows that the vascular system is acutely damaged by severe burns, resulting in prolonged hospitalization (Romero et al. 2018). A recent study showed that exposure to $43^{\circ} \mathrm{C}$ for a few hours can cause the upregulation of heat shock proteins and irreversible cellular membrane disruption in cardiac microvascular ECs (Zhang et al. 2020b).

Numerous reports have demonstrated that TS-induced cellular damage is exponential and dependent on energy accumulation, determined by the temperature and duration of exposure (Log 2017). The activation energy for the temperature range is approximately $120-150 \mathrm{kcal} / \mathrm{mole}$, which is consistent with the suppression of the activity of proteins and enzymes (Morris CC 1977). In the present study, our findings reveal that exposure to TS at $45^{\circ} \mathrm{C}$ for 10 minutes might evoke irreversible damage in primary ECs from mouse brain microvessel. TS suppressed proliferation via cell cycle arrest, resulting in an increase in betagal-positive cells and apoptotic cells. Further investigation demonstrated that TS also negatively regulated EC functions, including cytoskeletal rearrangement, tube formation and cellular motility. Comparison of the mRNA levels yielded consistent findings and suggested that TS might activate the TNF signalling pathway, resulting in the upregulation of pro-inflammatory factors, such as IL-1b and IL-6.

Although our present study lacks clarification of the mechanism underlying these therapeutic challenges, our data demonstrate that exposure to TS at $45^{\circ} \mathrm{C}$ for 10 minutes is sufficient to destroy essential functions of ECs, such as proliferation, migration and tube formation. Altogether, our findings suggest the importance of early interventions for protecting EC viability and function to improve wound healing and tissue repair.

\section{Declarations}

\section{Ethical Approval and Consent to participate}

This study was reviewed and approved by the Institutional Ethics Committee of the First Hospital of Jilin University.

\section{Consent for publication}

Written informed consent for publication was obtained from all participants. 
Availability of supporting data

The datasets generated for this study are available on request to the corresponding author.

\section{Competing interests}

The authors declare no conflict of interest.

\section{Funding}

This work was supported by grants from the NSFC (81302611 and 81701641), Natural Science Foundation of Science and Technology Department of Jilin Province (20190201037JC), Jilin Provincial Department of Finance (2018SCZWSZX-040), Jilin Provincial Department of Education (JJKH20201035KJ), JDYY Grant (2018-ZL-11).

\section{Authors' contributions}

$W Z$ and $B C$ performed most of the experiments and $X Z$ analyzed data. SY $Z$ and $X F$ performed densitometry and immunofluorescence analysis. $K X C$ and JA $Y$ conceived, designed, and supervised all studies. KX C and B C wrote the manuscript. All authors read and approved the final manuscript.

\section{Acknowledgements}

The authors thank Dr. Ting Yang (Laboratory of Cancer Precision Medicine, The First Hospital of Jilin University) for her useful suggestions.

\section{Authors' information}

Wei Zhao, Department of Cardiology, The First Hospital of Jilin University, Changchun, China.

Bo Chen, Department of Neurotrauma, The First Hospital of Jilin University, Changchun, China.

Xi Zhang, Department of Burn Surgery, The First Hospital of Jilin University, Changchun, China.

Shu-Yan Zhang, Department of Neurotrauma, The First Hospital of Jilin University, Changchun, China.

Xing Fan, Department of Burn Surgery, The First Hospital of Jilin University, Changchun, China.

Jia-Ao Yu, Department of Burn Surgery, The First Hospital of Jilin University, Changchun, China.

Ke-Xin Chen, Department of Burn Surgery, The First Hospital of Jilin University, Changchun, China.

\section{References}

AIRD WC. 2007. Phenotypic heterogeneity of the endothelium: I. Structure, function, and mechanisms. Circulation research 100: 158-173. 
CHURCH D, ELSAYED S, REID O, WINSTON B AND LINDSAY R. 2006. Burn wound infections. Clinical microbiology reviews 19: 403-434.

FLOREA V, BHAGAVATULA N, SIMOVIC G, MACEDO FY, FOCK RA AND RODRIGUES CO. 2013. c-Myc is essential to prevent endothelial pro-inflammatory senescent phenotype. PloS one 8: e73146.

GAO Q, CHEN K, GAO L, ZHENG Y AND YANG YG. 2016. Thrombospondin-1 signaling through CD47 inhibits cell cycle progression and induces senescence in endothelial cells. Cell death \& disease 7: e2368.

HIRTH D, MCCLAIN SA, SINGER AJ AND CLARK RA. 2013. Endothelial necrosis at 1 hour postburn predicts progression of tissue injury. Wound repair and regeneration : official publication of the Wound Healing Society [and] the European Tissue Repair Society 21: 563-570.

HUANG X, DAI Z, CAI L, SUN K, CHO J, ALBERTINE KH, MALIK AB, SCHRAUFNAGEL DE AND ZHAO YY. 2016. Endothelial p110yPI3K Mediates Endothelial Regeneration and Vascular Repair After Inflammatory Vascular Injury. Circulation 133: 1093-1103.

JACKSON DM. 1953. [The diagnosis of the depth of burning]. The British journal of surgery 40: $588-596$.

JESCHKE MG, GAUGLITZ GG, SONG J, KULP GA, FINNERTY CC, COX RA, BARRAL JM, HERNDON DN AND BOEHNING D. 2009. Calcium and ER stress mediate hepatic apoptosis after burn injury. Journal of cellular and molecular medicine 13: 1857-1865.

KUILMAN T, MICHALOGLOU C, MOOI WJ AND PEEPER DS. 2010. The essence of senescence. Genes \& Development 24: 2463-2479.

LANIER ST, MCCLAIN SA, LIN F, SINGER AJ AND CLARK RA. 2011. Spatiotemporal progression of cell death in the zone of ischemia surrounding burns. Wound repair and regeneration : official publication of the Wound Healing Society [and] the European Tissue Repair Society 19: 622-632.

LOG T. 2017. Modeling Skin Injury from Hot Spills on Clothing. International journal of environmental research and public health 14 .

MCDONALD AI ET AL. 2018. Endothelial Regeneration of Large Vessels Is a Biphasic Process Driven by Local Cells with Distinct Proliferative Capacities. Cell stem cell 23: 210-225.e216.

MENG LB, CHEN K, ZHANG YM AND GONG T. 2018. Common Injuries and Repair Mechanisms in the Endothelial Lining. Chinese medical journal 131: 2338-2345.

MITTAL M, SIDDIQUI MR, TRAN K, REDDY SP AND MALIK AB. 2014. Reactive oxygen species in inflammation and tissue injury. Antioxidants \& redox signaling 20: 1126-1167.

MORITZ ARAH, F.C. 1947. Studies of Thermal Injury. II. The Relative Importance of Time and Surface Temperature in the Causation of Cutaneous Burns. American Journal of Pathology 23: 695-720. 
MORRIS CC MR, FIELD SB. 1977. The response of the rat tail to hyperthermia. Br J Radiol 50: 5.

PORTER C, TOMPKINS RG, FINNERTY CC, SIDOSSIS LS, SUMAN OE AND HERNDON DN. 2016. The metabolic stress response to burn trauma: current understanding and therapies. Lancet (London, England) 388: 1417-1426.

REHO JJ, GUO DF AND RAHMOUNI K. 2019. Mechanistic Target of Rapamycin Complex 1 Signaling Modulates Vascular Endothelial Function Through Reactive Oxygen Species. Journal of the American Heart Association 8: e010662.

ROMERO SA, MORALEZ G, JAFFERY MF, HUANG M AND CRANDALL CG. 2018. Vasodilator function is impaired in burn injury survivors. American Journal of Physiology-Regulatory, Integrative and Comparative Physiology 315: R1054-R1060.

SINGH V, DEVGAN L, BHAT S AND MILNER SM. 2007. The pathogenesis of burn wound conversion. Annals of plastic surgery 59: 109-115.

SZCZESNY B, BRUNY NSZKI A, AHMAD A, OL H G, PORTER C, TOLIVER-KINSKY T, SIDOSSIS L, HERNDON DN AND SZABO C. 2015. Time-Dependent and Organ-Specific Changes in Mitochondrial Function, Mitochondrial DNA Integrity, Oxidative Stress and Mononuclear Cell Infiltration in a Mouse Model of Burn Injury. PloS one 10: e0143730.

TIWARI VK. 2012. Burn wound: How it differs from other wounds? Indian J Plast Surg 45: 364-373.

TOJKANDER S, GATEVA G AND LAPPALAINEN P. 2012. Actin stress fibers - assembly, dynamics and biological roles. Journal of Cell Science 125: 1855-1864.

WERNER S AND GROSE R. 2003. Regulation of wound healing by growth factors and cytokines. Physiological reviews 83: 835-870.

ZHANG X, CHEN B, WU J, SHA J, YANG B, ZHU J, SUN J, HARTUNG J AND BAO E. 2020a. Aspirin Enhances the Protection of Hsp90 from Heat-Stressed Injury in Cardiac Microvascular Endothelial Cells Through PI3K-Akt and PKM2 Pathways. Cells 9.

ZHANG X, CHEN B, WU J, SHA J, YANG B, ZHU J, SUN J, HARTUNG J AND BAO E. 2020b. Aspirin Enhances the Protection of Hsp90 from Heat-Stressed Injury in Cardiac Microvascular Endothelial Cells Through PI3K-Akt and PKM2 Pathways. Cells 9: 243.

ZHANG X ET AL. 2010. Impaired angiogenesis and mobilization of circulating angiogenic cells in HIF-1a heterozygous-null mice after burn wounding. Wound Repair and Regeneration 18: 193-201.

\section{Figures}


a

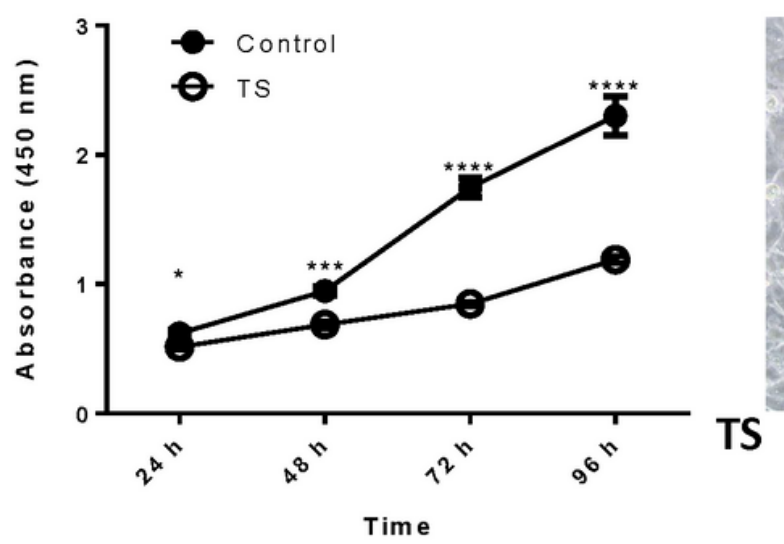

C

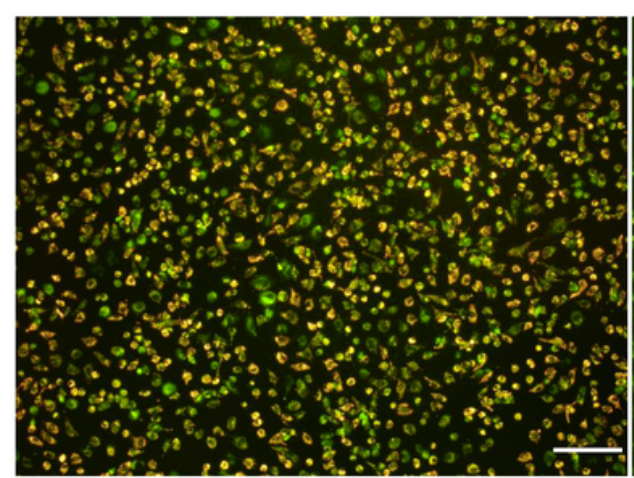

TS

b
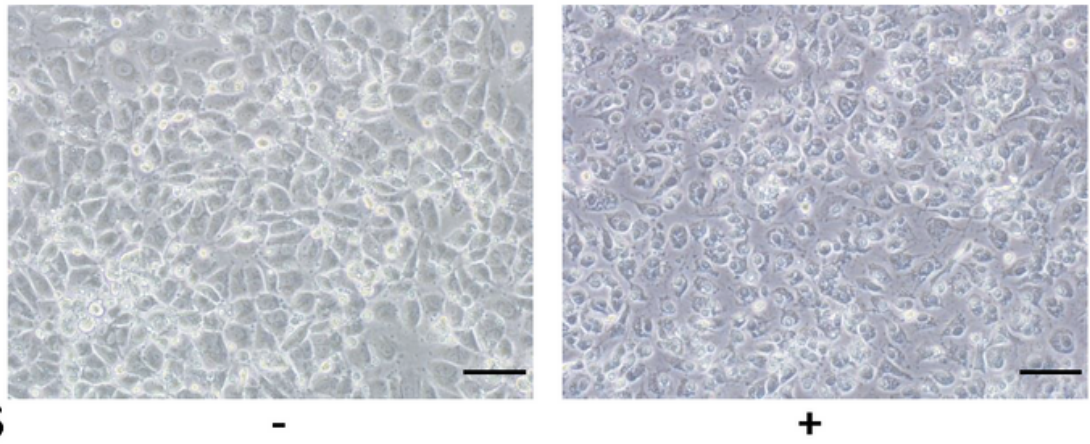

d
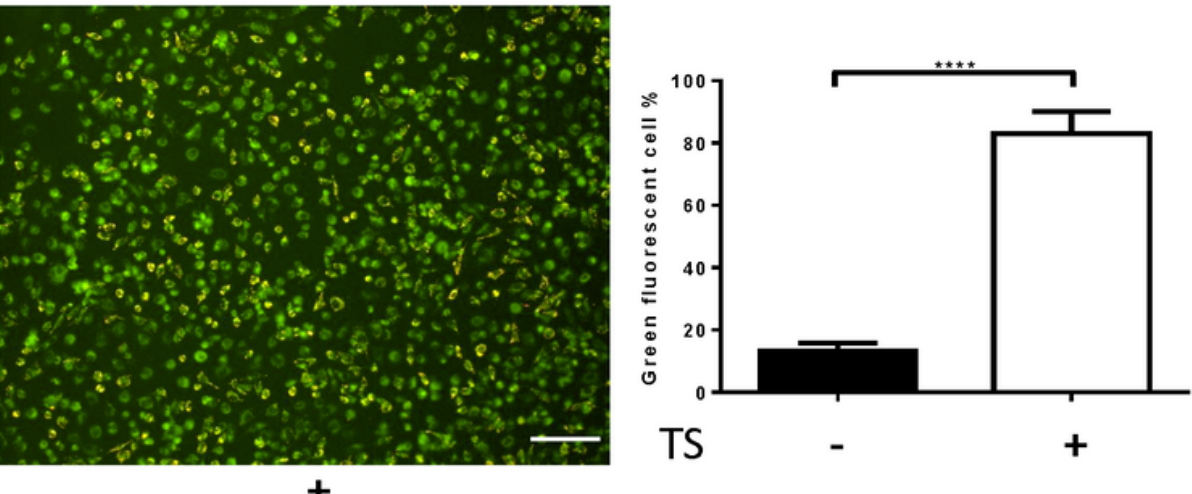

Figure 1

TS suppressed proliferation and promoted apoptosis in primary ECs. (a) Comparison of proliferation between ECs in the control and TS groups. Data from 3 independent experiments are shown (mean \pm SD). (b) Phenotype change in ECs at 96 hours after exposure to TS. Images from a representative of 6 random fields are shown. The scale bar represents $50 \mu \mathrm{m}$. (c) Image of JC- 1 staining in ECs at 96 hours after exposure to TS. Images from a representative of 6 random fields are shown. Scale bar represents 200 $\mu \mathrm{m}$. (d) Apoptosis was determined by the percentage of green fluorescent cells. Data from three independent experiments are shown (mean \pm SD). ${ }^{\star}, p<0.05 ; * \star *, p<0.005 ; * \star \star \star, p<0.001$. 
a

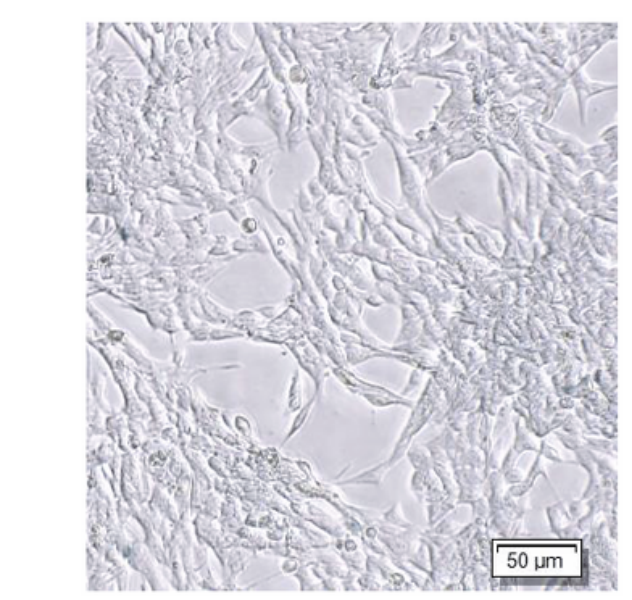

TS

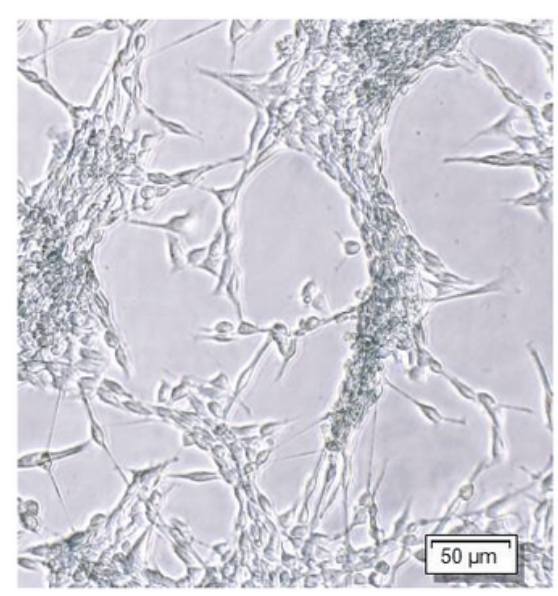

b

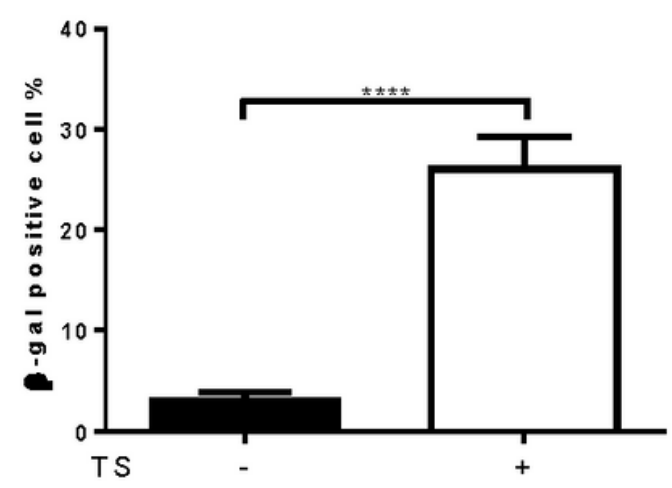

C

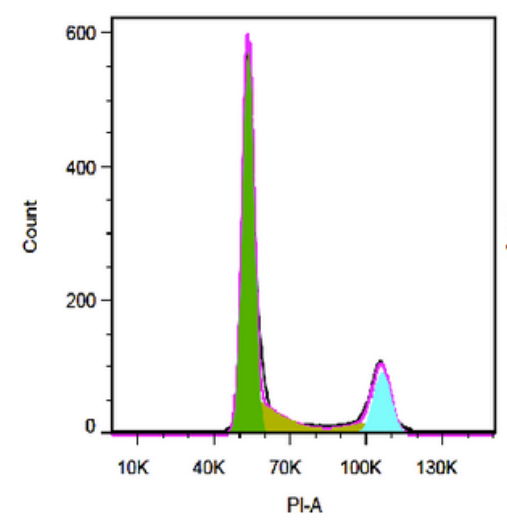

TS

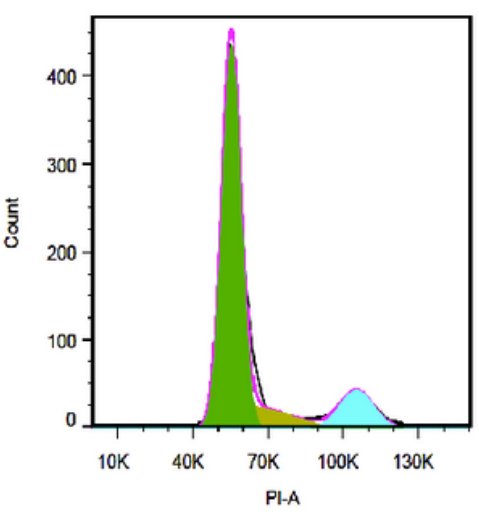

$+$

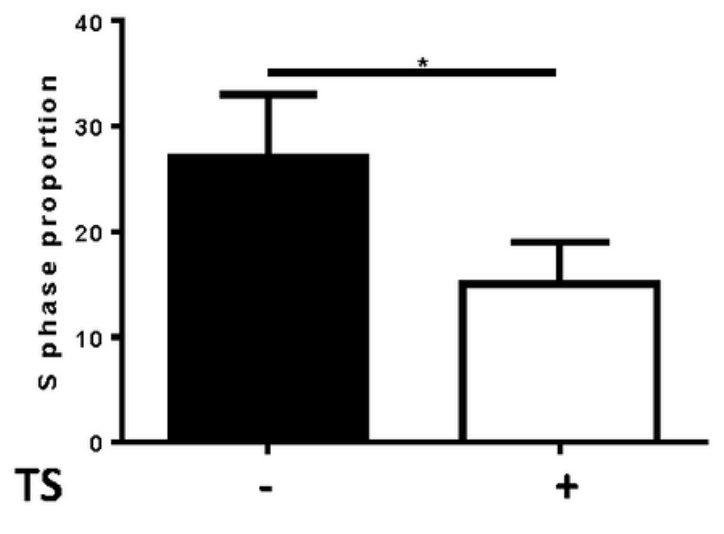

Figure 2

TS facilitated senescence and delayed the cell cycle in primary ECs. (a) Representative images of SA- $\beta$ gal staining and (b) percentage of senescent (SA- $\beta$-gal-positive) cells at 24 hours after exposure to TS (senescent cells are stained green). Images from a representative of 6 random fields are shown. The scale bar represents $50 \mu \mathrm{m}$. (c) Comparison of the $S$ phase ratio between the two groups of ECs. The graph represents the mean percentage of cells in the $S$ phase of the cell cycle determined by the DNA content. Data from 3 experiments are combined and presented as the mean $\pm S D$. ${ }^{*}, p<0.05, * \star \star \star, p<0.001$. 
b

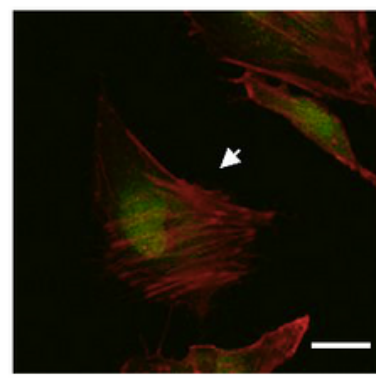

S

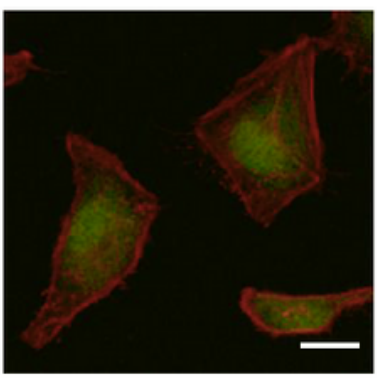

$+$

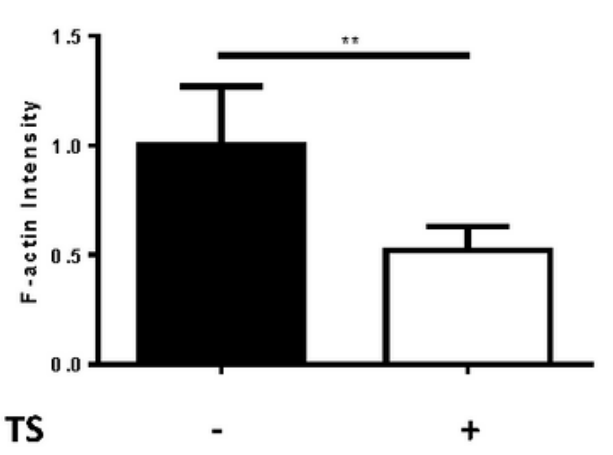

d

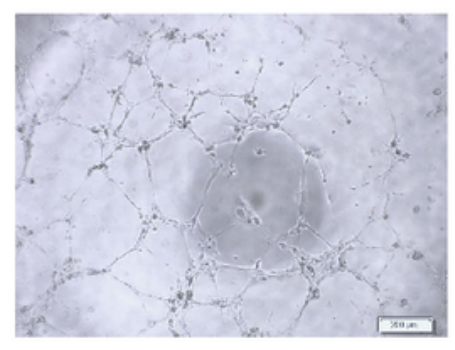

S

e

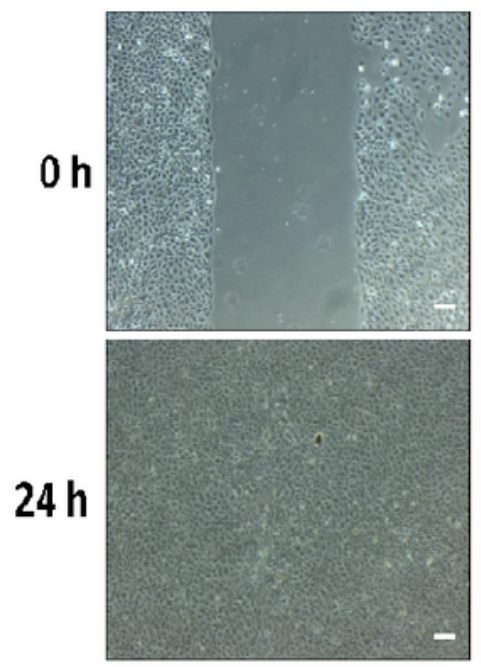

TS
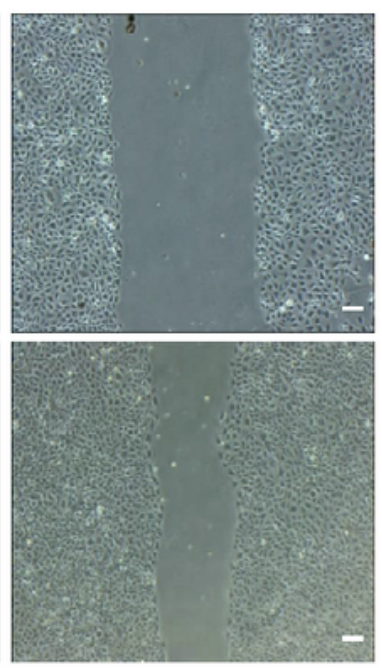

$+$

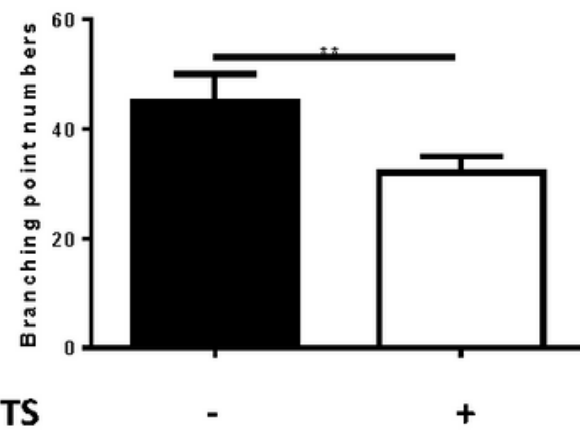

f

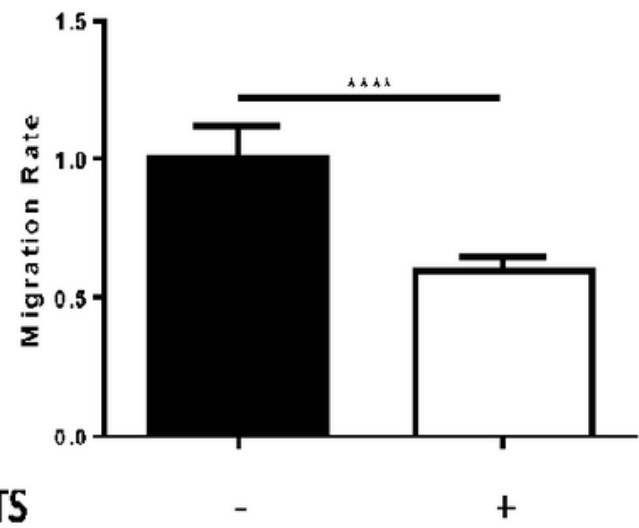

\section{Figure 3}

TS suppressed tube formation and cellular motility via disruption of cytoskeletal rearrangement in ECs.

(a) Stress fiber formation determined by Alexa Fluor 546 phalloidin staining (red). The scale bar represents $10 \mu \mathrm{m}$. (b) F-actin intensity determined by evaluating six randomly selected fields using ImagePro Plus 6.0 software. (c-d) The effect of TS exposure on angiogenesis was determined by tube formation assay. Representative images (c; scale bar, $200 \mu \mathrm{m}$ ) and the number of branch points/field (d) 
at 24 hours after exposure are shown. The data shown are from one representative experiment of two. (ef) The effect of TS exposure on motility was determined by migration assay at 24 hours after exposure. Images from a representative of 6 random fields are shown. The migration rate was quantified by measuring four different wound areas. Scale bar represents $200 \mu \mathrm{m}$. Data are presented as the mean \pm $\operatorname{SD}(n \geq 3) . * \star, p<0.01 ; * \star \star \star, p<0.001$.

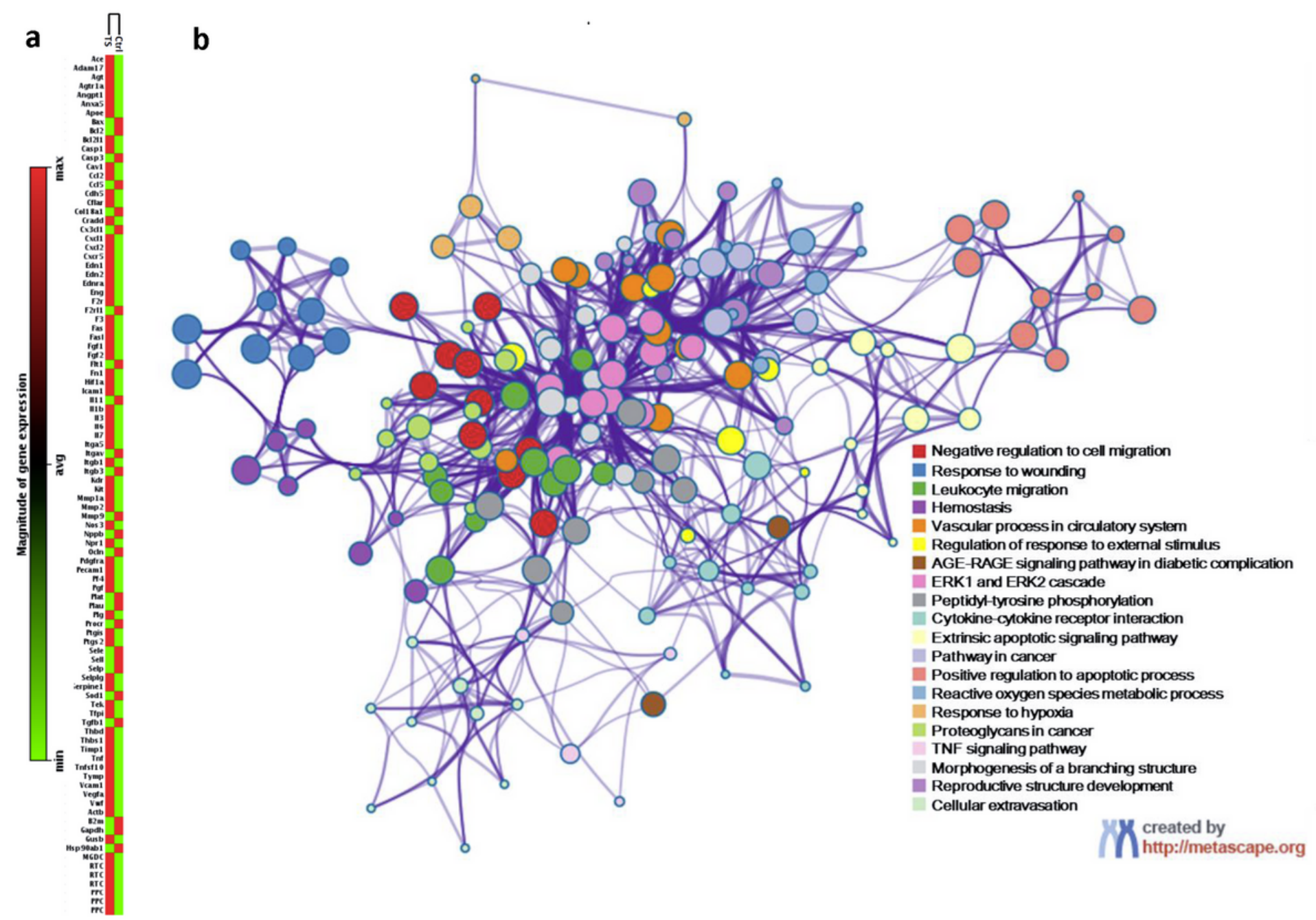

Figure 4

TS altered endothelial biology-related mRNA expression in primary ECs. (a) Clustergram of mRNA levels in ECs in the TS and control groups created using an mRNA array with non-supervised hierarchical clustering of the entire dataset to display a heat map with dendrograms indicating co-regulated genes across the two groups. (b) Changes analysed by GO enrichment analysis. 
a

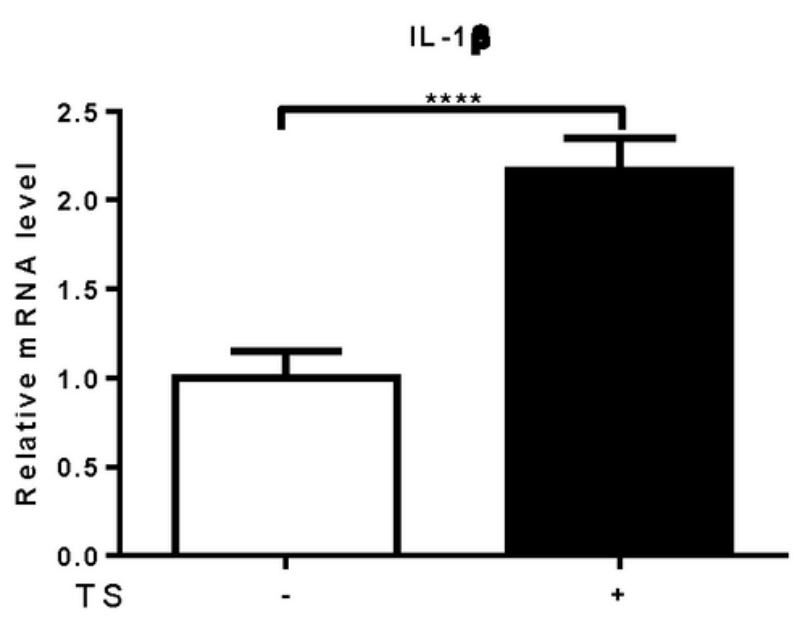

b

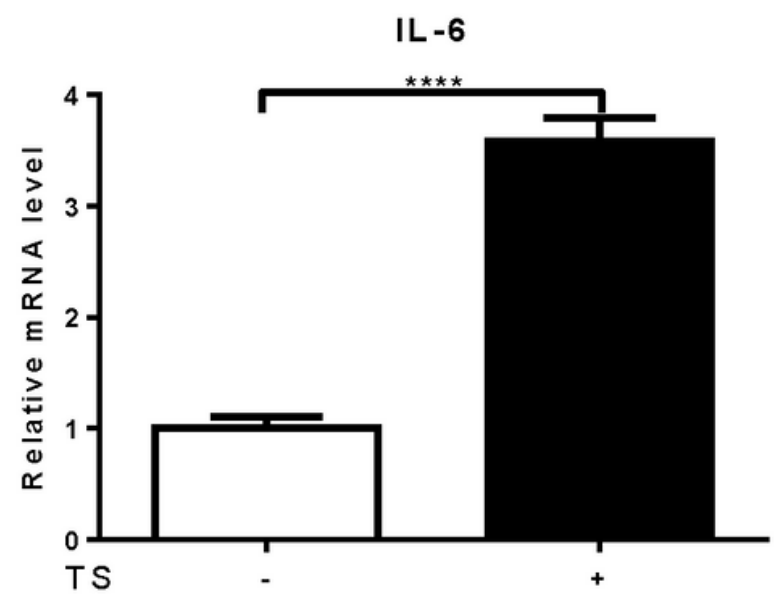

Figure 5

TS promoted pro-inflammatory factor expression in ECs. ( $a$ and $b$ ) Relative mRNA levels of IL-1 $\beta(a)$ and IL-6 (b). Gene expression levels were determined by quantitative real-time PCR and normalized to $\beta$-actin. Data from three experiments with essentially the same results were combined and are presented as the mean \pm SD. ${ }^{* \star * *}, p<0.001$.

\section{Supplementary Files}

This is a list of supplementary files associated with this preprint. Click to download.

- Figs1.png 